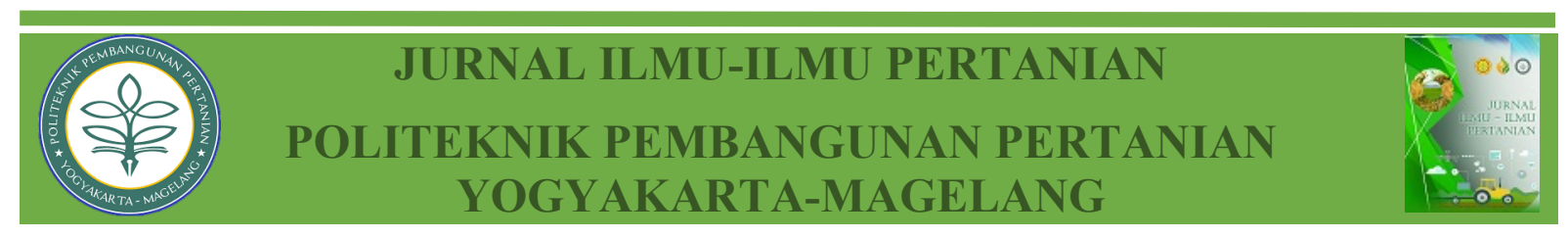

\title{
PENGARUH SISTEM PEMBELIAN TEBU (SPT) TERHADAP PENERIMAAN INSENTIF PETANI TEBU DI PABRIK GULA (PG.) KEBUN TEBU MAS
}

\author{
Amallia Ferhat ${ }^{1}$ \\ ${ }^{1}$ Jurusan Sosial Ekonomi, Fakultas Pertanian, Institut Pertanian STIPER Yogyakarta, Yogyakarta, \\ 55281 \\ Received \\ December $11^{\text {th }}, 2021$ \\ Accepted \\ December $28^{\text {th }}, 2021$ \\ Published \\ : December $31^{\text {st }}, 2021$ \\ Copyright Notice

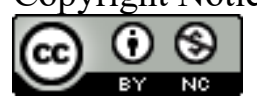 \\ : Authors retain copyright and grant the journal right of first \\ publication with This work is licensed under a Creative Commons \\ Attribution-Non Commercial 4.0 International License.
}

\begin{abstract}
ABSTRAK: Tujuan penelitian ini adalah menganalisis pengaruh sistem pembelian tebu terhadap pendapatan petani tebu di Pabrik Gula Kebun Tebu Mas. Dasar metode penelitian menggunakan metode survei dengan teknik purposive sampling. Jumlah sampel yang digunakan pada penelitian ini berjumlah 50 orang petani, yang dipilih atas dasar melakukan registrasi berulang selama dua tahun. Menjawab tujuan pada penelitian ini, maka data dianalisis menggunakan analisis regresi linier berganda, dengan bobot tebu sebagai X1, nilai rendemen adalah X2 dan X3 adalah lebih basis pengiriman. Data sampel dan pendukung lainnya pada penelitian menggunakan data primer dan sekunder yang langsung diperoleh langsung dari pabrik gula. Hasil penelitian menunjukkan variabel bobot tebu, nilai rendemen dan lebih basis memberikan pengaruh simultan terhadap penerimaan insentif petani. Apabila tidak terdapat pengaruh dari ketiga variabel tersebut, penerimaan petani hanya sebesar Rp. 96.824.142 per Ha atau bahkan terjadi penurunan. Sementara pada penerimaan insentif petani meningkat sebesar Rp. 42.273 .920 per Ha dari bobot tebu, Rp. 179.415 dari nilai rendemen dan Rp. 116.620 apabila terjadi peningkatan setiap 1\% dari masing-masing variabel.
\end{abstract}

Kata kunci: bobot tebu, kelebihan basis, produksi, rendemen

ABSTRACT: The aim of this study was to analyze the effect of the sugar cane purchasing system on the income of sugarcane farmers at the Sugar Factory Sugar Cane Plantation Mas. The basic research method is the survey method with the purposive sampling technique. The number of samples used in this study amounted to 50 farmers, who were selected on the basis of repeated registration for two years. Answering the objectives of this study, the data were analyzed using multiple linear regression analysis, with the weight of sugarcane as $X_{1}$, the yield value is $X_{2}$ and $X_{3}$ is more on the basis of delivery. The sample and other supporting data in this study used primary and secondary data which were directly obtained from the sugar factory. The results showed that the sugar cane weight variable, yield value and more basis gave a simultaneous effect on farmers' incentive receipts. If there is no influence from these three variables, the farmer's income is only Rp. 96,824,142 per Ha or even decreased.

\footnotetext{
*Email Penulis Korespondensi: amallia@instiperjogja.ac.id
} 
Meanwhile, the farmers' incentive received increased by Rp. 42,273,920 per Ha of sugar cane weight, Rp. 179,415 of the yield value and Rp. 116,620 if there is an increase of every 1\% of each variable.

Keywords: excess shipping base, incentive, production, weight, sugarcane yeild

\section{PENDAHULUAN}

Industri berbasis perkebunan mempunyai kemampuan sebagai leading sector dalam pertumbuhan ekonomi seperti lapangan kerja, pergerakan nilai tukar serta mendorong perbaikan distribusi pendapatan petani. Gula merupakan salah satu special product dan strategis bagi masyarakat. Gula menjadi penting tidak hanya bagi konsumen sebagai pengguna akhir, namun bagi kalangan industri sebagai produsen yang mengolah komoditi gula menjadi produk dengan value added tersendiri (Friyatno \& Agustian, 2014). Kebutuhan gula konsumsi langsung berbasis tebu sebesar 3,2 juta ton dan kebutuhan gula industri sebesar 2,5 juta ton. Hal ini tidak berbanding lurus dengan produksi gula nasional yang hanya mencapai 2,1 juta (Ferhat \& Mulyo, 2018). Ketidakseimbangan antara produksi gula dan konsumsi gula dalam hal ini gula kristal putih (GKP), dipicu oleh ketidakmampuan pabrik dalam menyediakan tebu sebagai bahan baku ditambah kondisi rata-rata pabrik gula di Indonesia yang tidak layak (Lestari et al, 2016).

Secara umum, kondisi pergulaan nasional saat ini lebih mengarah pada masalah on farm. Masalah on farm yang terjadi tidak khusus hanya mengarah pada teknis budidaya, melainkan pada pelaku budidaya itu sendiri yakni petani. Petani merupakan unsur penting dalam perannya sebagai pelaksana budidaya, cash flow, jadwal panen (tebang, muat, angkut) dan bentuk pengambilan keputusan lainnya (Ismail, 2018). Dalam upaya penyediaan bahan baku giling, dukungan bagi petani menjadi satu hal yang penting baik dalam pembinaan dan pembiayaan. Tujuan dari adanya perlakuan khusus yaitu untuk meningkatkan trust antar petani, petani ke pabrik gula dan petani ke pemerintahan. Kepercayaan antar setiap pengguna dan pelaku dalam konteks industri menjadi satu hal yang sangat penting untuk dirawat. Pada siklus industri pergulaan, petani membutuhkan pabrik gula baik BUMN ataupun Swasta untuk mengolah dan menaungi mereka dari segala risiko.

Pabrik gula pada disisi industri membutuhkan petani sebagai produsen bahan tebu serta mitra yang berkaitan dengan pemberdayaan. Peran perusahaan sebagai distributor atau sebagai pemberi pinjaman dalam hal ini berperan terhadap distribusi gula hingga tingkat end users dan memberikan pendanaan bagi petani yang dipercayakan melalui pabrik-pabrik gula. Pada ujung siklus, tentunya ada peran serta pemerintah di dalamnya. Pada titik ini, pemerintah berperan sebagai pembina, pengelola yang bertugas menjembatani antara petani, pabrik gula, perusahaan dalam satu wadah.

Tidak dapat dipungkiri, persaingan di setiap lini industri semakin lama semakin meningkat. Hal tersebut yang nantinya mengharuskan adanya terobosan dalam pengembangan teknologi serta policy yang mengarah pada peningkatan efisiensi dan efektivitas bisnis industri gula (Yunitasari et al, 2015). Pada penelitian ini, fokus utama kegiatan yang dilihat yaitu pada pengelolaan petani dan pendapatan petani. Berikut ini merupakan rangkaian dari kebijakan dalam upaya meningkatkan produksi tebu dengan meningkatkan kinerja petani, yaitu 1) intensifikasi lahan; 2) melakukan ekstensifikasi atau penambahan luas areal; 3) revitalisasi lahan, 4) regrouping lahan; 5) pelaksanaan sistem pembelian tebu. 
Sebelum diberlakukannya sistem pembelian tebu (SPT), proses pembayaran tebu dilakukan dengan sistem bagi hasil $(\mathrm{SBH})$. Dalam pelaksanaan sistem bagi hasil, penerimaan petani didasarkan atas rendemen rata-rata pabrik gula. Apabila rendemen berada kisaran 7\%, maka pembagiannya terdiri dari $66 \%$ gula milik petani dan $3 \%$ tetes. Sementara gula bagian pabrik gula sebesar $34 \%$. Bila rendemen lebih dari $9 \%$ maka persentase gula bagian petani dapat mencapai $75 \%$ dengan tetes 2,5\%. Pada sistem bagi hasil, nilai - nilai di atas tadi tidak secara total diperoleh petani. Petani masih dikenakan beberapa biaya tambahan, seperti :

1. Pengolahan gula

2. Pengemasan

3. Administrasi

Tabel di bawah ini merupakan proporsi pembagian hasil baik gula maupun tetes, yang digunakan sebagai rujukan dalam penentuan pendapatan petani berdasarkan sistem bagi hasil.

Tabel 1. Proporsi Antara Bagi Hasil Gula dan Tetes Petani Sesuai Instruksi Pemerintah

\begin{tabular}{lcr}
\hline $\begin{array}{c}\text { Rendemen } \\
(\%)\end{array}$ & $\begin{array}{c}\text { Bagian Gula } \\
\text { PTR } \\
(\%)\end{array}$ & $\begin{array}{c}\text { Bagian Tetes } \\
\text { PTR } \\
(\%)\end{array}$ \\
\hline Minimal 7 & $66,0 \%$ & $3,00 \%$ \\
$7-8$ & $70,0 \%$ & $2,75 \%$ \\
$8-9$ & $72,5 \%$ & $2,50 \%$ \\
Lebih dari 9 & $75,0 \%$ & $2,50 \%$ \\
\hline \multicolumn{3}{c}{ (sumber: Litbang, 2012) }
\end{tabular}

Sesuai pada Tabel 1, pembayaran kepada petani pada sistem bagi hasil dilakukan setiap satu periode lelang atau \pm per 14 hari giling.

Berdasarkan Surat Edaran No. 593/ TI. 050/E/7/2019 yang dikeluarkan oleh Kementerian Pertanian melalui Direktorat Jendral Perkebunan, menyatakan bahwa Sistem Pembelian Tebu (SPT) adalah sistem pembelian tebu petani oleh Pabrik Gula secara langsung dengan harga pembelian yang ditetapkan pemerintah sesuai kualitas tebu. Mekanisme pembelian tebu atau sistem beli putus ditetapkan berdasarkan Harga Pembelian Tebu Pekebun (HPP) sebesar Rp. 51.000 per kuintal atau Rp. 510.000 per ton pada tingkat rendemen 7\%. Jika rendemen lebih tinggi atau kurang dari 7\%, maka harga disesuaikan secara proporsional. Sistem Pembelian Tebu secara umum dihitung dengan rumus, sebagai berikut:

$$
\mathrm{SPT}=\mathrm{R} / 7 \text { \% } \times \text { Rp. } 510 \text { per } \mathrm{Kg}
$$

Insentif adalah penghargaan yang diberikan berdasarkan atas prestasi kerja seseorang. Maka semakin tinggi prestasi kerja seseorang dalam hal ini adalah petani tebu, maka semakin tinggi pula insentif yang diterima (Zakaria, 2013). Sementara menurut Mangkunegara (2004) dalam Prawira dan Ariastita (2014), mengemukakan bahwa insentif adalah bentuk penghargaan atas dasar kerja yang tinggi serta bentuk pengakuan dari perusahaan. Jenis- jenis insentif terdiri dari 1) insentif individu atau imbalan atas usaha yang dilakukan seseorang atau petani secara individu, 2) insentif kelompok atau bentuk penerimaan yang dibagi atas jumlah anggota kelompok. Pemberian insentif kelompok banyak dilakukan di pabrik gula yang menerapkan sistem bagi hasil (SBH).

Sementara pada sistem pembelian tebu, pembayaran tebu petani yang didasari atas rendemen dan bobot tebu. Pelaksanaan analisis hasil dilakukan selama \pm 2 hari dengan menggunakan Analisis Rendemen Individu (ARI). Melalui sistem pembelian tebu, petani secara tidak langsung diuntungkan karena tidak terbebani dengan kondisi pabrik yang sedang berjalan dan biaya-biaya yang berkaitan dengan pengolahan. Disisi lain sistem pembelian tebu diharapkan dapat mendorong peningkatan efisiensi. Berikut merupakan data tingkat rendemen dan nilai pembelian tebu di PG. Kebun Tebu Mas, yang disajikan pada Tabel 2.

Pada sistem pembelian tebu, penerimaan petani didasari atas nilai rendemen yang diukur dengan core sampler menggunakan pendekatan Nera-Infrared Spectroscopy 
(NIRS). Adapun tujuan dari penggunaan NIRs yaitu memperoleh persentase rendemen dengan lebih akurat, transparansi hasil, serta yang terpenting sebagai upaya meningkatkan trust antara petani dan pabrik gula. Pengukuran rendemen dengan core sampler, dapat dilakukan dengan:

1. Tebu dalam keadaan masak optimal ( Brix $=20$ atau Brix $>20$ )

2. Bebas dari sampah, serasah daun kering, serta sogolan

3. Tebu tebangan tidak boleh terpapar udara luar lebih dari 1 x 24 jam (Illia, 2017).

Tabel 2. Tingkat Rendemen dan Nilai Pembelian Tebu PG. Kebun Tebu Mas

\begin{tabular}{cc}
\hline $\begin{array}{c}\text { Rendemen } \\
\text { Tebu } \\
(\%)\end{array}$ & $\begin{array}{c}\text { Harga Rendemen Per } \\
\text { Kuintal Tebu } \\
(\mathrm{Rp} / \mathrm{Kw})\end{array}$ \\
\hline 6 & 50.000 \\
6,5 & 55.000 \\
7 & 69.000 \\
7,5 & 74.000 \\
8 & 78.900 \\
8,5 & 84.200 \\
9 & 89.500 \\
9,5 & 98.400 \\
10 & 100.100 \\
\hline (sumber: data primer pembelian tebu PG. Kebun \\
\multicolumn{2}{c}{ Tebu Mas, 2019) }
\end{tabular}

Selain upaya terhadap peningkatan produktivitas tebu, sistem pembelian tebu juga berpengaruh pada besarnya insentif yang diterima petani. Penerimaan insentif petani didasari atas kelebihan basis atau kelebihan jarak pengiriman antara batas maksimum jarak pabrik dan kebun tebu. Dalam penerapan di lapangan, Pabrik Gula Kebun Tebu Mas Jawa Timur, menerapkan sistem pembelian tebu pada seluruh petani mitra. Berikut ini merupakan data acuan besarnya insentif yang akan diterima petani, berdasarkan kelebihan basis atau kelebihan jarak pengiriman antara batas maksimum jarak pabrik dan kebun tebu, yang disajikan pada Tabel 3. Dalam pelaksanaan penentuan standar atau proses pendataan tebu masuk, PG. Kebun Tebu Mas menggunakan pihak eksternal sebagai tenaga ahli dan pelaksana audit internal. Maka berdasarkan uraian di atas, tujuan dilaksanakannya penelitian ini yaitu untuk menganalisis pengaruh sistem pembelian tebu terhadap penerimaan insentif petani berdasarkan bobot tebu, rendemen dan lebih basis.

Tabel 3. Nilai Kelebihan Basis Pengiriman Tebu Yang Dibayar di PG. Kebun Tebu Mas

\begin{tabular}{lc}
\hline Jarak & $\begin{array}{c}\text { Harga } \\
(\mathrm{Km})\end{array}$ \\
\hline $50-100$ & Rm $/ \mathrm{Kw})$ \\
$150-200$ & Rp. 2.500 \\
$250-300$ & Rp. 3.500 \\
\hline
\end{tabular}

Sumber: Data Primer Pembelian Tebu PG. Kebun Tebu Mas, 2019.

\section{METODE}

Penelitian ini dilakukan di Pabrik Gula (PG) Kebun Tebu Mas Lamongan, Jawa Timur. Pemilihan lokasi tersebut didasari pada beberapa pertimbangan, seperti 1) PG. Kebun Tebu Mas termasuk dalam salah satu pabrik gula di Jawa yang memiliki kapasitas giling besar, yaitu 10.000 ton cane per day (TCD), hal ini tentunya menjadikan PG. Kebun Tebu Mas membutuhkan pasokan bahan baku giling yang juga tinggi; 2) PG. Kebun Tebu Mas memiliki 2 jenis pola kemitraan yaitu petani binaan dan petani lepas; 3) PG. Kebun Tebu Mas berdiri di jalur historis PTPN X, yang memungkinkan terjadinya perebutan tebu giling. Penelitian ini dilaksanakan pada bulan September s/d November 2020.

Pengumpulan data primer maupun sekunder pada penelitian ini, menggunakan metode survei langsung ke objek penelitian. Data yang terkumpul kemudian diolah berdasarkan persamaan (1), yang teknis pelaksanaannya ditambahkan komponen lebih basis pengiriman tebu. Pengambilan sampel menggunakan metode purposive sampling, seperti yang telah dijelaskan pada pertimbangan penentuan lokasi. Dalam penelitian ini, sebanyak 50 orang petani yang digunakan menjadi sampel dengan kriteria pertimbangan petani tersebut melakukan registrasi berulang ( 2 
tahun berturut - turut). Data yang digunakan terdiri dari data sekunder (identitas petani), data primer (produksi, rendemen, kelebihan basis pengiriman). Untuk memperkuat hasil analisis, peneliti menggunakan analisis regresi linier berganda. Variabel yang digunakan sebagai faktor penentu penerimaan insentif terdiri dari bobot tebu, nilai rendemen $\leq$ (rendemen yang sudah dikonversi ke rupiah) dan kelebihan basis (kelebihan jarak pengiriman tebu). Tahapan yang dilakukan sebelum melakukan pengujian dengan analisis regresi linier berganda yaitu melakukan uji asumsi klasik. Di mana uji asumsi klasik yang dimaksud terdiri dari uji normalitas, uji multikolinearitas dan uji heteroskedastisitas. Setelah diperoleh hasil dari analisis regresi linier berganda, berikutnya yaitu melakukan pembahasan pada hasil uji Adjusted $R$ Square, uji F dan uji t $(t-t e s t)$.

\section{Uji Normalitas}

Uji normalitas dilakukan untuk mengetahui distribusi normal dari model regresi. Distribusi normal dari model regresi dilihat melalui hasil uji Kolmogorov - Smirnov. Kriteria pengambilan keputusan dapat dilakukan jika nilai signifikan lebih besar dari 0,05 (Sig > 0,05), maka model dinyatakan terdistribusi normal. Jika yang terjadi adalah sebaliknya, maka data pada model tidak terdistribusi normal (Kanita \& Hendryadi, 2017).

\section{Uji Multikolinearitas}

Uji multikolinearitas merupakan uji yang digunakan untuk mengetahui adanya hubungan linier antar variabel independen. Persamaan yang baik, adalah persamaan yang tidak memuat lebih dari satu hubungan nyata variabel independen. Model dinyatakan mengalami multikolinearitas apabila nilai Tolerance lebih dari 0,1 (Tolerance $>0,1)$ dan nilai VIF lebih kecil dari 10 (VIF < 10) (Denziana dkk, 2014).

\section{Uji Heteroskedastisitas}

heteroskedastisitas merupan uji yang untuk melihat ada tidaknya sebaran varian yang sama pada nilai absolute residual. Teknik pengujian menggunakan uji Glesjer. Pengambilan keputusan dapat dilakukan apabila:

- Nilai absolute residual $>0,05$, maka tidak terjadi masalah heteroskedastisitas.

- Nilai absolute residual <0,05, maka terjadi heteroskedastisitas (Cai \& Hayes, 2008)

Setelah uji asumsi klasik sudah dilaksanakan dan hasil analisis regresi diperoleh, tahapan berikutnya adalah melakukan uji Adjusted $R$ Square, uji F dan uji t (t- test). Adjusted $R$ Square merupakan nilai $R$ Square yang telah disesuaikan. Nilai Adjusted R Square akan selalu lebih kecil dari nilai $R$ Square dan bisa bernilai negatif. Uji $F$ atau uji koefisien secara serentak, merupakan uji untuk mengetahui tingkat signifikansi antara $\mathrm{X}$ dan $\mathrm{Y}$. Kriteria dalam uji $\mathrm{F}$, yaitu:

Jika $\mathrm{F}_{\text {hitung }} \leq \mathrm{F}_{\text {tabel}}$, maka $\mathrm{HO}$ diterima Jika $\mathrm{F}_{\text {hitung }}>\mathrm{F}_{\text {tabel}}$, maka $\mathrm{H} 0$ ditolak

Dengan asumsi, apabila $\mathrm{F}_{\text {hitung }}$ lebih besar, artinya terjadi pengaruh secara simultan antara variabel independen terhadap dependen.

Uji $t$ ( $t$ - test) digunakan untuk mengetahui apakah variabel independen (X) berpengaruh terhadap variabel dependen (Y). Dengan kriteria sebagai berikut :

Jika $-\mathrm{t}_{\text {tabel }} \leq \mathrm{t}_{\text {hitung }} \leq+\mathrm{t}_{\text {tabel }}$ maka Ho diterima dan Ha ditolak

Jika $t_{\text {hitung }} \leq-t_{\text {tabel }}$ atau $t_{\text {hitung }}>+t_{\text {tabel }}$ maka Ho ditolak dan Ha diterima

Berdasarkan seluruh tahapan pengujian, diperoleh persamaan regresi sebagai berikut:

Di mana:

$$
\mathbf{Y}=\boldsymbol{\alpha}+\mathbf{b}_{1} \mathbf{X}_{1}+\mathbf{b}_{2} \mathbf{I} \mathbf{X}_{2}+\mathbf{b}_{3} \mathbf{X}_{3}+\boldsymbol{\mu}
$$

$\mathrm{Y} \quad=$ Penerimaan insentif $(\mathrm{Rp})$

$\alpha \quad=$ Nilai konstanta

b1 ...bn $=$ Koefisien regresi

$\mathrm{X}_{1} \quad=$ Bobot tebu $(\mathrm{Kw})$ 


$$
\begin{array}{ll}
\mathrm{X}_{2} & =\text { Nilai rendemen }(\mathrm{Rp}) \\
\mathrm{X}_{3} & =\text { Lebih basis }(\mathrm{Rp}) \\
\mu & =\text { Error atau faktor kesalahan }
\end{array}
$$

\section{HASIL DAN PEMBAHASAN}

Menjawab tujuan penelitian ini, yaitu untuk menganalisis pengaruh sistem pembelian tebu berdasarkan bobot tebu, rendmeen dan lebih basis, analisis yang digunakan yaitu analisis regresi linier berganda. Tahapan awal yang dilakukan sebelum melakukan analisis linier berganda yaitu melakukan uji asumsi klasik untuk mengetahui apakah data yang tersedia dapat dilakukan analisis lanjutan. Hasil uji normalitas nantinya digunakan untuk membuktikan apakah model regresi yang telah diuji terdistribusi normal. Hail tersebut diperoleh berdasarkan nilai Asymp Sig. 0,200 lebih besar dari 0,05 (0,200 > $0,05)$. Selain itu gambar Normal Probability Plot juga menunjukkan data model regresi tersebar disekitar garis diagonal dan mengikuti arah diagonal, yang menunjukkan data terdistribusi normal.

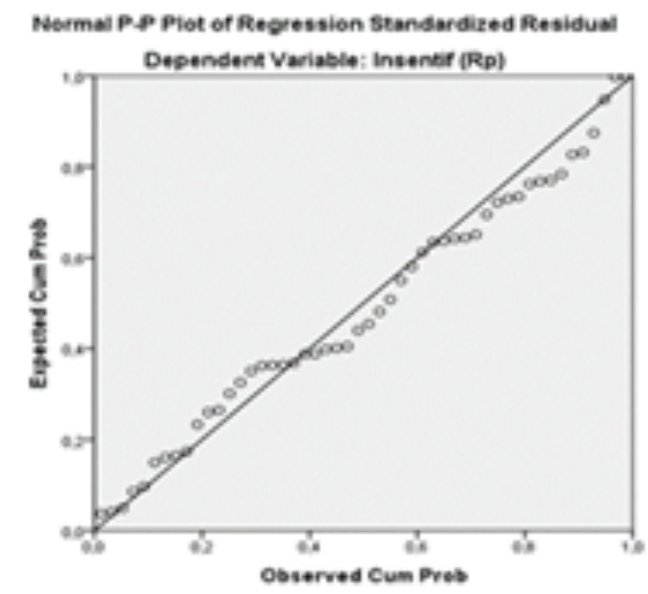

Gambar 1. Normal Probability Plot Model Regresi Pengaruh Sistem Pembelian Tebu Terhadap Penerimaan Insentif.

(sumber: hasil analisis, 2020)

Sedangkan hasil uji multikolinieritas, menunjukkan model regresi ini terbebas dari masalah multikolinieritas. Hal ini terbukti dari nilai Collinearity Tolerance variabel bobot tebu, nilai rendemen dan lebih basis lebih besar dari 0,1 . Sementara nilai VIF dari ketiga variabel lebih kecil dari 10. Hasil pengujian tersebut dapat dilihat pada tabel dibawah ini.

Tabel 4. Hasil Uji Multikoliniearitas

\begin{tabular}{lcc}
\hline Model & Coefficient & \\
\cline { 2 - 3 } & $\begin{array}{c}\text { Collinearity } \\
\text { Tolerance }\end{array}$ & $\begin{array}{c}\text { Statistic } \\
\text { VIF }\end{array}$ \\
\hline $\mathrm{X}_{1}$ Bobot Tebu & 0,152 & 6,563 \\
$\mathrm{X}_{2}$ Nilai Rendemen & 0,807 & 1,239 \\
$\mathrm{X}_{3}$ Lebih Basis & 0,140 & 7,153 \\
\hline
\end{tabular}

(sumber: hasil analisis, 2020)

Hasil uji heteroskidastisistas, nilai variabel bobot tebu $\left(\mathrm{X}_{1}\right)$, nilai rendemen $\left(\mathrm{X}_{2}\right)$ dan lebih basis $\left(\mathrm{X}_{3}\right)$ lebih besar dari 0,05 (Sig. $>0,05$ ). Maka model regresi ini dinyatakan bebas dari heteroskidastisitas, sehinga secara keseluruhan model regresi ini layak untuk diuji pada tahapan selanjutnya. Nilai Adjusted $R$ Square yang diperoleh yang diperoleh pada variabel bobot tebu, nilai rendemen dan lebih basis sebesar 0,955 atau 95,5\% mempengaruhi penerimaan insentif petani. Sisa pengujian sebesar 4,5\% dipengaruhi oleh variabel lain yang tidak ada dalam penelitian. Hasil analisis regresi linier dapat dilihat pada Tabel 5.

Hasil uji F, nilai $F_{\text {hitung }}$ sebesar 351,517 dan $F_{\text {tabel }}$ sebesar 2,787 atau 351, $517>$ 2,787, sedangkan nilai signifikansi pada uji F sebesar 0,000 lebih kecil dari 0,05 atau $0,000<0,05$. Di mana variabel bobot tebu, nilai rendemen, kelebihan basis dinyatakan secara simultan berpengaruh terhadap penerimaan insentif. Untuk hasil uji t atau $t$ - test, pengujian dilakukan pada tingkat kepercayaan $99 \%(\alpha=0,01)$ pada taraf signifikansi 0,01 . Maka diperoleh nilai signifikansi bobot tebu, nilai rendemen dan kelebihan basis lebih kecil dari 0,01 atau sig $<0,01$, yang berarti terjadi pengaruh secara parsial pada penerimaan insentif. Apabila mengacu pada Tabel 5 diatas, diperoleh persamaan regresi sebagai berikut:

$$
\mathrm{Y}=-\mathbf{- 9 6 . 8 2 4 . 1 4 2 , 6}+42.273,92 \mathrm{X}_{1}+
$$


Di mana:

$\mathrm{Y} \quad=$ Penerimaan Insentif $(\mathrm{Rp})$

$\mathrm{X}_{1} \quad=$ Bobot Tebu $(\mathrm{Kw})$

$\mathrm{X}_{2} \quad=$ Nilai Rendemen (Rp)

$\mathrm{X}_{3} \quad=$ Kelebihan Basis $(\mathrm{Rp})$

Nilai konstanta yang diperoleh dari pengaruh tiap - tiap variabel yaitu sebesar -94.824.142,6 dan nilai signifikansi sebesar $0,000(0,000<0,01)$ pada tingkat kepercayaan 99\%. Di mana hal ini berarti penerimaan hanya sebesar Rp. 94. 824. 142,6 per Ha tanpa adanya pengaruh dari tiap-tiap variabel. Nilai koefisien regresi variabel bobot tebu sebesar 42.273,92 dengan nilai signifikansi sebesar 0,000 $(0,000<0,01)$ pada tingkat kepercayaan $99 \%$, di mana setiap penambahan bobot tebu petani yang masuk ke PG. Kebun Tebu Mas sebesar 1\%, akan menambah penerimaan insentif petani sebesar Rp. 42.273,92 per Ha. Koefisien regresi variabel nilai rendemen sebesar 179,41 dan nilai signifikansi sebesar $0,000(0,000<$ $0,01)$ pada tingkat kepercayaan $99 \%$. Hal ini berarti setiap terjadi penambahan nilai rendemen sebesar $1 \%$, maka penerimaan insentif meningkat sebesar Rp. 179.410.

Tabel 5. Hasil Uji Regresi Pengaruh Sistem Pembelian Tebu Terhadap Penerimaan Insentif Petani Tebu di PG. Kebun Tebu Mas Tahun 2020

\begin{tabular}{lllll}
\hline Variabel & $\begin{array}{l}\text { Tanda } \\
\text { Harapan }\end{array}$ & Koefisien Regresi & t-hitung & Sig. t \\
& + & $42.273,92^{* * *}$ & & 0,000 \\
$\mathrm{X}_{1}$ Bobot Tebu & + & $179,415^{* * *}$ & 8,519 & 0,000 \\
$\mathrm{X}_{2}$ Nilai Rendemen & + & $11,662^{* * *}$ & 6,783 & 0,004 \\
$\mathrm{X}_{3}$ Lebih Basis & $+/-$ & $-96.824 .142,6^{* * *}$ & 3,018 & -000 \\
Constant & & 0,958 & $-6,985$ & \\
\hline $\mathrm{R}^{2}$ & & 0,955 & & \\
Adjusted R & & 351,517 & & \\
F-hitung & & 0,000 & & \\
Sig & & & \\
\hline
\end{tabular}

Keterangan:

$* * *$ taraf signifikansi 0,01 pada tingkat kepercayaan $99 \%$

** taraf signifikansi 0,05 pada tingkat kepercayaan $95 \%$

* taraf signifikansi 0,10 pada tingkat kepercayaan $90 \%$

Variabel kelebihan basis dengan nilai koefisien regresi yaitu sebesar 11,62 serta nilai signifikansi sebesar 0,004 $(0,004<$ $0,01)$ pada tingkat kepercayaan sebesar $99 \%$, yang artinya setiap terjadi penambahan jarak sebesar $1 \%$ maka terjadi penambahan insentif sebesar 11,62 atau sebesar Rp. 116.200.

\section{SIMPULAN DAN SARAN}

Kesimpulan penelitian ini yaitu penerimaan insentif petani di PG. Kebun Tebu Mas secara umum dipengaruhi bobot tebu, nilai rendemen lebih basis pengiriman tebu dari lokasi kebun. Mengacu pada hasil analisis, penerimaan petani hanya akan sebesar Rp. 96.842.142 apabila tidak dipengaruhi variabel bobot tebu, nilai rendemen dan lebih basis. Sementara penerimaan insentif akan meningkat sebesar Rp. 42. 273.920 dari bobot tebu, Rp. 179.410 dari nilai rendemen dan Rp. 116.200 dari lebih basis apabila tiap-tiap variabelnya meningkat setiap 1\%. Dengan kata lain apabila ketiga variabel atau dua dari ketiga variabel tersebut meningkat, maka secara simultan penerimaan insentif petani juga meningkat.

Metode pembayaran dengan sistem pembelian tebu harus lebih banyak di terapkan di pabrik-pabrik gula milik BUMN ataupun swasta. Dalam 
menganalisis pengaruh sistem pembelian tebu, alat analisis yang digunakan tidak terbatas pada analisis regresi linier berganda, sehingga penulis selanjutnya yang ingin melakukan penelitian serupa dengan judul ini dapat mengembangkan dengan model analisis yang berbeda dan lebih variatif.

\section{PUSTAKA ACUAN}

Cai, L., \& Hayes, A. F. (2008). A new test of linear hypotheses in OLS regression under heteroscedasticity of unknown form. Journal of Educational and Behavioral Statistics, 33(1), 21-40. https://doi.org/10.3102/10769986073 02628

Denziana Angrita, Indrayenti, F. F. (2014). Corporate Financial Performance Effects of Macro Economic Factors Against Stock Return. Akutansi Dan Keuangan, 5, 19-39. Retrieved from http://jurnal.ubl.ac.id/index.php/jak/ar ticle/view/542/509

Ferhat, A., \& Mulyo, J. H. (2018). Dampak Regrouping Lahan Terhadap Produksi Tebu Petani Berdasarkan Penggunaan Input di Pabrik Gula Gempolkrep Jawa Timur The Effect of Land Regrouping on Sugarcane Production Depending on The Usage of Input Factor in Gempolkrep Sugar Company of East Java. Habitat, 29(3), 113-121.

https://doi.org/10.21776/ub.habitat.20 18.029.3.14

Friyatno, S., \& Agustian, A. (2014). Analisis Perkembangan Produksi, Konsumsi dan Impor Gula di Indonesia. Prosiding Seminar Nasional Pengembangan Teknologi Pertanian, (Pentingnya Gula), 474482. Retrieved from jurnal.polinela.ac.id

Illia, S. (2017). Seminar Nasional. In Mutu Tebu Industri Gula Di Indonesia (pp. 94-100). Jember. Retrieved from https://fp.ub.ac.id/semnas2017/materi /paralel/materi 17.pdf

Imam Ridlo Ismail. (2018). Sinergitas Stakeholder Dalam Pengembangan Tanaman Tebu, 6(April), 1-8. Retrieved from http://journal.unair.ac.id/

Kanita, N. R., \& Hendryadi, H. (2017). Faktor Determinan Pembentuk Struktur Modal Pada Perusahaan Sektor Farmasi Periode 2012 - 2016. Jurnal Riset Manajemen Dan Bisnis (JRMB) Fakultas Ekonomi UNIAT, 2(September), 241-250. https://doi.org/10.36226/jrmb.v2is1.5 7

Lestari, E. K., Fauzi, A., Hutagaol, M. P., \& Hidayat, A. (2016). Analysis of sugarcane farming in the sugar mill District Semboro Jember, Indonesia : a data envelopment analysis application. International Journal of ScLestari, E. K., Fauzi, A., Hutagaol, M. P., \& Hidayat, A. (2016). Analysis of Sugarcane Farming in the Sugar Mill District Semboro Jember , Indonesia: A Data Envelopment Analysis Application. International Journal of Sciences: , 25(2), 157-171. Retrieved from http://gssrr.org/index.php?journal=Jo urnalOfBasicAndApplied\&page $=$ artic le\&op=view\&path $\% 5 B \% 5 \mathrm{D}=5165$

Litbang. (2012). Kementerian Pertanian. Retrieved February 20, 2020, from http://perkebunan.litbang.pertanian.g o.id/rekomendasi-kebijakan-sistembeli-putus-tebu/

Prawira, N. G. A., \& Ariastita, P. G. (2014). Rumusan Insentif dan Disinsentif Pengendalian Konversi Lahan Pertanian di Kabupaten Gianyar. Jurnal Teknik Pomits, 3(2), 255-260. https://doi.org/http://dx.doi.org/10.12 962/j23373539.v3i2.7295

Yunitasari, D., Hakim, D., Juanda, B., \& Nurmalina, R. (2015). Menuju Swasembada Gula Nasional: Model Kebijakan Untuk Meningkatkan Produksi Gula Dan Pendapatan Petani 
Tebu Di Jawa Timur. Jurnal Ekonomi Kebijakan Publik, 6(2012), 1-15. https://doi.org/https://doi.org/10.2221 2/jekp.v6i1.160

Zakaria, A. K. (2013). Implementasi Sosialisasi Insentif Ekonomi Dalam Pelaksanaan Program Perlindungan Lahan Pertanian Pangan Berkelanjutan (PLP2B). Forum Penelitian Agro Ekonomi, 31, 137149.

https://doi.org/http://dx.doi.org/10.21

082/fae.v31n2.2013.137-149 